\title{
CARACTERIZACIÓN DE LA FARMACOCINÉTICA DEL ETANOL (PISCO SOUR), EN ANESTESISTAS Y RESIDENTES DE ANESTESIA
}

\author{
Cortínez Luis Ignacioํㅜㄹ Rolle Augusto ${ }^{1}$, Mertz Verónica ${ }^{1}$, Contreras Víctor ${ }^{1}$, \\ Paredes Sebastián ${ }^{1}$, Fuentes Ricardo ${ }^{1}$ \\ 1 División de Anestesiología, Facultad de Medicina. Pontificia Universidad Católica de Chile.
}

Introducción: Es sabido que los anestesistas tienen debilidad por el pisco sour. Caracterizar la farmacocinética del alcohol luego de beber una copa de pisco sour puede permitir una dosificación más racional de esta deliciosa bebida, en especial considerando la nueva ley de tránsito.

Objetivo General: Crear un modelo farmacocinético de etanol en ingesta única, vía oral.

Material y Métodos: Estudio observacional, de carácter transversal. 22 sacrificados anestesistas y/o residentes de anestesia mayores de 18 años aceptaron participar. Se solicitó ayuno de $2 \mathrm{~h}$ previo a colección de datos. Se registraron variables antropométricas y se midió masa grasa visceral con bioimpedanciometro. Todos ingirieron una copa de pisco sour, con 22,4 g de etanol, de manera rápida, por una vez. Se realizaron mediciones seriadas por alcohotest, a los 5, 10, 15, 30, 45, 60 y 90 minutos. Se permitió ingerir alimentos solo luego de tomada la última medición de alcohotest. Se utilizó programa NONMEM7.3 en la construcción del modelo farmacocinético. Se consideró una disminución de la función objetiva de NONMEM (OFV, -2Likelihood) de al menos 3,84 puntos, como cambio significativo, correspondiente a $\mathrm{p}<0,05$.

Resultados: Se analizaron los datos de 22 sujetos (15 hombres). Descripción de la muestra, variables expresadas en Media y (Rango): edad 34,5 años (25-46), peso 80,2 kg (61-122), IMC $27,4 \mathrm{~kg} \cdot \mathrm{m}^{-2}(21,4-36,2)$, Masa grasa visceral 25,9 $\mathrm{kg}(11,9-47,5)$. Las mujeres alcanzaron mayores concentraciones de alcohol que los hombres (figura 1). Un modelo de 1 compartimento con absorción de primer orden y eliminación de orden cero, fue superior al modelo equivalente con eliminación de primer orden $(\triangle \mathrm{OFV}-42,49)$.
El ajuste de volumen de distribución y velocidad máxima de aclaramiento (Vmax) por peso total mejoró la predicción del modelo $(\Delta \mathrm{OFV}$ $11,08)$. El ajuste por masa magra no fue superior al ajuste por peso total $(\triangle \mathrm{OFV}-0,16)$. Las mujeres tienen en promedio menor Vmax que los hombres $(0,152$ vs $0,282 \mathrm{mg} / \mathrm{h} ; \Delta \mathrm{OFV}-3,86)$. La edad no fue una covariable significativa en nuestra muestra.

Conclusiones: Nuestros resultados confirman una eliminación saturable del alcohol y un mayor riesgo de toxicidad en mujeres. La dosis de alcohol debe ajustarse a peso y género. Otras covariables como el hábito alcohólico y la edad no pudieron analizarse adecuadamente por la reducida representatividad de la muestra y datos poco confiables entregados por algunos sujetos.

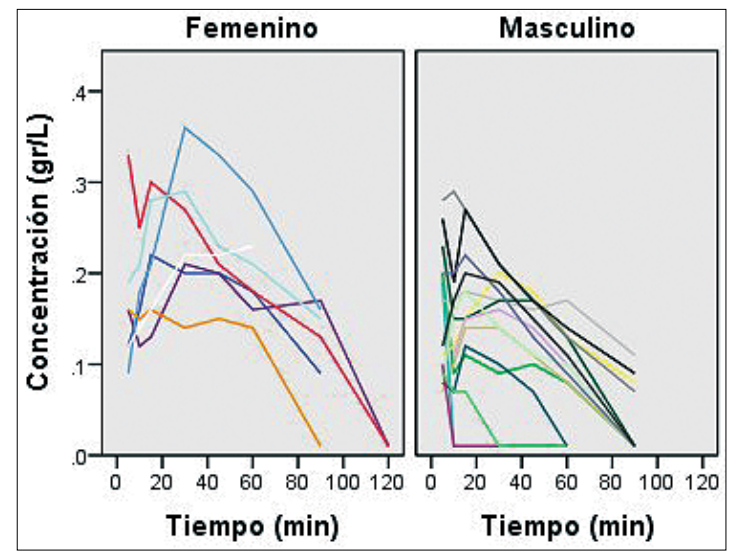

Figura 1. 